\title{
Drug Resistance Trends and Patterns of Mycobacterium Tuberculosis Isolates from Pulmonary Tuberculosis Patients at a Tertiary Care Hospital in Turkey
}

\author{
Esra Yazar ${ }^{1 *}$, Pinar Yildiz¹, Gulsah Gunluoglu¹, Sedat Altin1, Veysel Yilmaz¹, Derya Gencer ${ }^{2}$, \\ Hatice Yazisiz ${ }^{3}$ \\ ${ }^{1}$ Pulmonary Medicine Department, Yedikule Chest Disease Education and Training Hospital, Yedikule, Istanbul \\ ${ }^{2}$ Infection Diseases Department, Yedikule Chest Disease Education and Training Hospital, Yedikule, Istanbul \\ ${ }^{3}$ Microbiology Department, Yedikule Chest Disease Education and Training Hospital, Yedikule, Istanbul \\ Email: esraertan76@yahoo.com, Pinary70@yahoo.com, gunluoglugulsah@yahoo.com, \\ sedataltin@yahoo.com, veysel@solunum.com.tr, deryagencer@gmail.com, drhyazisiz@yahoo.com
}

Received 19 September 2014; revised 24 October 2014; accepted 5 November 2014

Copyright (C) 2014 by authors and Scientific Research Publishing Inc.

This work is licensed under the Creative Commons Attribution International License (CC BY).

http://creativecommons.org/licenses/by/4.0/

c) (i) Open Access

\begin{abstract}
Background: We aim to determine the proportions and patterns of resistance to first-line drugs: isoniazid (H), rifampicin (R), ethambutol (E) and streptomycin (S) among pulmonary tuberculosis patients. Methods: Strains were obtained from 1584 culture positive pulmonary tuberculosis patients. All specimens were inoculated into Löwenstein-Jensen media (LJ) and TK selective; drug susceptibility tests (DST) were performed for first-line drugs. Results: Multidrug resistant (MDR) were detected in $146(9.2 \%)$ isolates. Three hundred (18.9\%) isolates were resistant to $\mathrm{H} ; 220$ (13.9\%) to R; 168 (10.6\%) to S; 137 (8.6\%) to E. Any drug resistance was detected in 442 (27.9\%) isolates. MDR rate was higher in male patients than females $(P=0.006)$. MDR rates were different according to the age groups $(P=0.02)$. The highest rate was in $35-44$ years and the lowest rate was in 15 - 24 years. Conclusions: We found an association between middle age and male gender and MDR tuberculosis.
\end{abstract}

\section{Keywords}

Tuberculosis, Drug Resistance Patterns, Drug Susceptibility Test

\footnotetext{
${ }^{*}$ Corresponding author.
} 


\section{Background}

With over eight million cases and two million deaths annually, tuberculosis (TB) remains a major cause of morbidity and mortality worldwide [1]. Recently, it has been shown that multidrug-resistance (MDR) is the most important cause for mortality in patients with tuberculosis [2] [3]. In 2012, the WHO reported estimated 310,000 MDR-TB cases among notified TB patients with pulmonary TB in 2011. Almost $60 \%$ of these cases were in India, China and Russian Federation [4].

A country suffering from MDR-TB cases ranged between 500 and over per year should be considered hot spots for MDR-TB [5]. There were 191 - 263 MDR-TB cases per year notified between the years of 2005 and 2009 in Turkey according to 2011 Turkey National Tuberculosis Report [6].

In our country, the main reason of drug resistance increase is the delay of TB control programmes application including DOTS (Direct Observation Therapy Strategy).

Turkey Ministry of Health began to implement WHO-DOTS for TB in 2003 and reported 100\% coverage by 2006. In this study, we aimed to determine the resistance patterns and proportion against the first-line antituberculosis drugs among pulmonary tuberculosis patients.

\section{Methods}

In this study, drug susceptibility testing (DST) results of 1584 culture positive sputum was analyzed retrospectively. Proportions and patterns of resistance to first-line drugs; isoniazid (H), rifampicin (R), ethambutol (E) and streptomycin (S) were searched among pulmonary tuberculosis (TB) patients. The study was carried out at the tuberculosis laboratory of Yedikule Chest Disease and Chest Surgery Education and Research Hospital, Istanbul, Turkey, between 2008 and 2010. We obtained the materials from patients with pulmonary TB with unknown treatment history.

Samples were decontaminated by the NaOH-NALC decontamination method using a ready to-use kit, Mycoprosafe (SALUBRIS). Decontamination solution contained $4 \% \mathrm{NaOH}$. From processed samples $0.5 \mathrm{ml}$ was inoculated into Löwenstein-Jensen media (LJ) and TK selective (TK SLC). TK SLC tubes were monitored by Mycolor TK. TK medium contains $\mathrm{pH}$ indicators, and the color change basicaly depends on $\mathrm{pH}$ change due to bacterial growth. Mycobacterial growth causes its original red color to turn yellow [7]. Löwenstein-Jensen tubes were incubated in a regular $37^{\circ} \mathrm{C}$ incubator. For susceptibility testing and M. Tuberculosis complex MOTT differentiation, $200 \mu \mathrm{L}$ from the liquid portion of TK SLC was transferred to the suspension tube of the TK Anti TB and PNB kit. After shaking with glass beads, $500 \mu \mathrm{L}$ of the suspension was transferred to a dilution tube that contained $4.5 \mathrm{~mL}$ of liquid to prepare a 1:10 dilution. From this diluted suspension, $200 \mu \mathrm{L}$ was inoculated into each tube. The tubes were placed into Mycolor TK which analyzes the growth in the control and drug-containing tubes. Mycolor TK reports the results as susceptible or resistant. Inhibition of growth in the PNB tube indicates that the isolate belongs to the M. Tuberculosis complex group, and growth in PNB indicates MOTT.

Drug critical concentrations were $0.2 \mu \mathrm{g} / \mathrm{mL}$ for $\mathrm{H}, 1.0 \mu \mathrm{g} / \mathrm{mL}$ for R, $7.5 \mu \mathrm{g} / \mathrm{mL}$ for E and $2 \mu \mathrm{g} / \mathrm{mL}$ for S. H37Rv strains is used for internal control strain for culture and DST.

If more than one susceptibility test was performed per patients during three years period, initial test results were accepted in that study.

Any drug resistance is indicated as total resistance for a drug with and without accompanying other drug resistance. Multi drug resistance is defined resistance to at least both isoniazid and rifampicin.

Istatistical Analysis

SPSS version 16.0 (SPSS Inc., Chicago, IL, USA) was used for statistical analysis. Patient demographics and disease characteristics were summarized using descriptive statistics. All numeric data were expressed as mean and standard deviation, and non-numeric data as frequency and percentage. Statistical mean difference between the groups was analyzed with Student t-test and in case of more than two groups with one-way ANOVA test. Chi-square test was used in non-numeric data. $\mathrm{P}$ value of $<0.05$ was considered significant.

\section{Results}

The mean age of cases was $38.6 \pm 16.6$ years; 1235 were (78\%) male. Resistance to any drug was found in $27.9 \%$, to $\mathrm{H}$ in $18.9 \%$, to $\mathrm{R}$ in $13.9 \%$, to $\mathrm{S}$ in $10.6 \%$ and to $\mathrm{E}$ in $8.6 \%$. Multidrug resistance rates (HR, HRE, HRS and HRES) were 9.2\%, 4.9\%, 4.7\% and 3.2\%, respectively (Figure 1).

The highest mono drug and MDR rates were determined in the year 2008. Results of drug susceptibility test- 
ing according to the years were given in Table 1.

MDR rates were different according to the age groups $(P=0.02)$. The highest MDR rate was in 35 - 44 years and the lowest rate was in 15 - 24 years. Multi drug resistance rates according to the ages were given in Table 2. Additionally MDR TB was higher in male patients $(\mathrm{n}=126,10.2 \%)$ than females $(\mathrm{n}=19,5.4 \%)(\mathrm{P}=0.006)$.

\section{Discussion}

Multidrug-resistance is the independent factor for morbidity and mortality due to tuberculosis [2] [3]. Treatment of MDR-TB is difficult and drugs used for treatment are less potent, more toxic and more expensive than first line drugs [8] [9].

In 2008, the WHO reported a worldwide MDR rate was 5.3\%. Similarly, the MDR rate in our country was

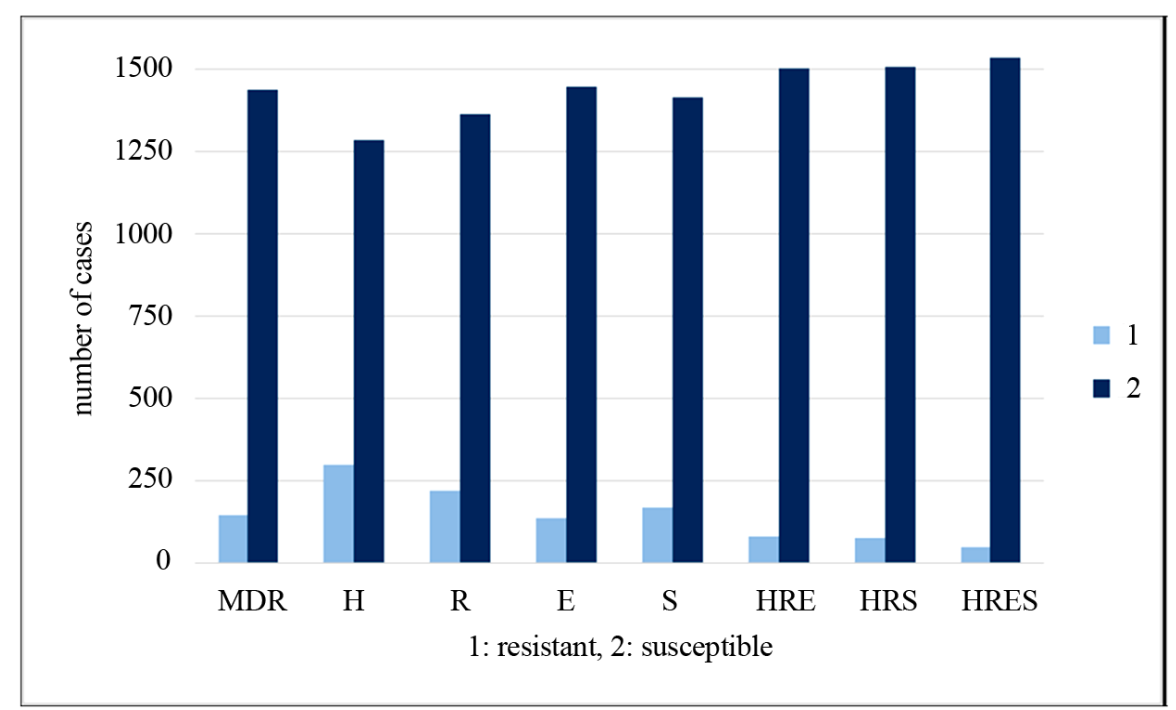

Figure 1. First-line drug susceptibility pattern in culture positive pulmonary tuberculosis cases in Turkey, 2008-2010.

Table 1. Patterns of first-line combined drug resistance in pulmonary tuberculosis according to the time periods.

\begin{tabular}{ccccccc}
\hline & H n (\%) & R n (\%) & S n (\%) & E n (\%) & MDR n (\%) & Total n (\%) \\
\hline 2008 & $166(26.5)$ & $59(13.5)$ & 9321.3 & $63(14.4)$ & $47(10.8)$ & 437 \\
2009 & $18(10.6)$ & $17(10)$ & $12(7.1)$ & $14(8.2)$ & $11(6.5)$ & 169 \\
2010 & $166(17)$ & $144(14.7)$ & $63(6.4)$ & $60(6.1)$ & $88(9)$ & 978 \\
$\mathbf{2 0 0 8 - 2 0 1 0}$ & $\mathbf{3 0 0 ( 1 8 . 9 )}$ & $\mathbf{2 2 0 ( 1 3 . 9 )}$ & $\mathbf{1 6 8 ( 1 0 . 6 )}$ & $\mathbf{1 3 7 ( 8 . 6 )}$ & $\mathbf{1 4 6}(\mathbf{9 . 2})$ & $\mathbf{1 5 8 4}$ \\
\hline
\end{tabular}

Table 2. Multi drug resistance rates in pulmonary tuberculosis according to the ages.

\begin{tabular}{cccc}
\hline Age (years) & MDR + n (\%) & MDR - n (\%) & Total \\
\hline $15-24$ & $26(6.9 \%)$ & $353(93.1 \%)$ & 379 \\
$25-34$ & $28(7.1)$ & $367(92.9)$ & 395 \\
$35-44$ & $36(13.6 \%)$ & $228(86.4 \%)$ & 264 \\
$45-54$ & $25(10.5 \%)$ & $214(89.5)$ & 239 \\
$\geq 55$ & $31(10.1 \%)$ & $276(89.9 \%)$ & 307 \\
Total & $\mathbf{1 4 6}(\mathbf{9 . 2 \% )}$ & $\mathbf{1 4 3 8 ( 9 0 . 8 \% )}$ & $\mathbf{1 5 8 4}$ \\
\hline
\end{tabular}


reported as 4.9\% - 5.3\% between the period of 2005-2009 years [6]. However, we found the rate of MDR TB in our hospital $(6.5 \%-10.8 \%)$ higher than this rate. Our hospital is the sole tertiary referral hospital of Istanbul Europe side; this might be the reason of our high MDR rate.

In this study MDR TB rate was higher in male patients (10.2\%) than females (5.4\%). Similarly, there were studies reported higher MDR TB rate in males [10] [11]. This issue could be attributed to behavioral factors for tuberculosis such as smoking, alcohol consumption and malnutrition higher in males than females and the delay in seeking medical treatment in men [12]. Another factor is higher number of males than females with tuberculosis. However, some studies reported no difference for the rate of MDR TB with respect to gender [13] [14].

We detected the highest MDR rate in the age group of 35 - 44 years. A previous study conducted in Vietnam, reported the highest MDR rate in the same age group [13]. In another study from Turkey, the highest MDR rate was reported in the age group of 30 - 39 years [15]. We found the lowest MDR rate in the age group of 15 - 24 years. Similarly, in the previous studies the lowest MDR rate was reported in the younger age groups (in the 10 19 and 15 - 24 age groups) [13] [14]. Presumably, the reason of the low MDR rate in the younger age is the more new TB cases in this age group.

In 2008, the WHO reported a worldwide resistance rate to $\mathrm{H}$ of $5.9 \%$. $\mathrm{H}$ resistance rates higher than $10 \%$ can predict the development of MDR TB according to the WHO [16]. The higher resistance rate of $\mathrm{H}$ according to other first line drugs may be resulted by both its wide use in the chemoprophylaxis and latent TB [17]. Resistance rate of $\mathrm{H}$ was declared between 11.5\% - 14.4\% in Turkey by National Tuberculosis Report 2011 [6]. In our study, we found the highest monoresistance against $\mathrm{H}$ (18.9\%). These results are a concern for the risk of developing of MDR TB in our country. On the other hand, we detected R resistance rate as $13.9 \%$. The resistance rate for $\mathrm{R}$ in Turkey has been reported between 6.5\% - 7.1\% [6]. This $\mathrm{R}$ resistance rate is also in close relation to MDR TB. Rifampicin resistance was found in approximately 5\% of strains, a high proportion of R resistance was associated with concurrent resistance to $\mathrm{H}$ [18]. Thus, the detection of resistance to $\mathrm{R}$ can be used as a marker for MDR-TB with a high level of accuracy [19].

Diagnosis and appropriate treatment of MDR-TB remain major challenges. Less than $5 \%$ of new and previously treated TB patients were tested for MDR-TB in most countries and the reported number of patients enrolled on treatment was equivalent to only 16\% of the 290,000 MDR-TB patients in 2010 [20]. Otherwise, each untreated MDR-TB patient infects 10 - 15 people every year according to the WHO [16]. And, this will carry more serious proportions problem of primary resistance in the future. In our country, using of DST for diagnosis and treatment of TB is increasing. The financial of diagnosis and treatment of MDR TB cases are supplied by the government in Turkey.

The limitation of this study was that treatment history of the patients was not known and therefore the primary and secondary resistance rate was not given. However, we gave the combine resistance rate of MDR TB cases showing the resistance pattern of bacilli in the environment. Actually, the combined resistance rate gives more accurate idea in comparison of countries with respect to resistance rate.

\section{Conclusion}

MDR TB may become an important problem in our health facilities unless TB control programs are strengthened and continuous systemic surveillance is applied. Notification of the DST results with clinical data is a key element to get valid and representative information on drug resistance. Additionally, we detected an association between age, gender and MDR TB. Whether age and gender could be considered as a risk factor for MDR TB or not, this issue should be investigated in more detailed studies.

\section{Competing Interests}

The authors declare that they have no financial or non-financial competing interests.

\section{References}

[1] Frieden, T.R., Sterling, T.R., Munsiff, S.S., Watt, C.J. and Dye, C. (2003) Tuberculosis. Lancet, 13, 887-899. http://dx.doi.org/10.1016/S0140-6736(03)14333-4

[2] Petrini, B. and Hoffner, S. (1999) Drug-Resistant and Multidrug-Resistant Tubercle Bacilli. International Journal of Antimicrobial Agents, 13, 93-97. http://dx.doi.org/10.1016/S0924-8579(99)00111-9 
[3] Pillay, M. and Sturm, A.W. (2007) Evolution of the Extensively Drug-Resistant F15/LAM4/KZN Strain of Mycobacterium Tuberculosis in KwaZulu-Natal, South Africa. Clinical Infectious Diseases, 45, 1409-1414. http://dx.doi.org/10.1086/522987

[4] WHO (2012) WHO 2012 Global Tuberculosis Report. World Health Organization, Geneva. http://www.who.int/tb/publications/global_report/en/

[5] Becerra, M.C., Farmer, P.E. and Kim, J.Y. (1999) The Problem of Drug-Resistant Tuberculosis: An Overview. In: The Global Impact of Drug Resistant Tuberculosis, Program in Infectious Disease and Social Change, Department of Social Medicine, Harvard Medical School, Boston, 1-38.

[6] (2011) 2011 Turkey National Tuberculosis Report. Turkish Government Tuberculosis Fight Ministry, Ankara, 47-75.

[7] Kocagöz, T., Altın, S., Türkyılmaz, Ö., et al. (2012) Efficiency of the TK Culture System in the Diagnosis of Tuberculosis. Diagnostic Microbiology and Infectious Disease, 72, 350-357. http://dx.doi.org/10.1016/j.diagmicrobio.2011.12.004

[8] Tahaoğlu, K., Törün, T., Sevim, T., et al. (2001) The Treatment of Multidrug-Resistant Tuberculosis in Turkey. The New England Journal of Medicine, 19, 170-174. http://dx.doi.org/10.1056/NEJM200107193450303

[9] Sevim, T., Aksoy, E., Ataç, G., et al. (2002) Treatment Adherence of 717 Patients with Tuberculosis in a Social Security System Hospital in Istanbul, Turkey. The International Journal of Tuberculosis and Lung Disease, 6, 25-31.

[10] Taha, N., Hamed, A., Qurechi, J.A., Ahmad, B. and Abraham, S. (2009) Rifampicin Resistance Profile of Mycobacterium Tuberculosis Isolated from Human Patients. Proceedings of the Pakistan Academy of Sciences, 46, 131-136.

[11] Willy, U., Fernand, M., Eduardo, V., et al. (2008) Primary Antimicrobial Resistance among Mycobacterium Tuberculosis Isolates from HIV Seropositive and HIV Seronegative Patients in Dares Salam Tanzania. BMC (Research Notes), 1, 58. http://dx.doi.org/10.1186/1756-0500-1-58

[12] Lönnroth, K., Jaramillo, E., Williams, B.G., Dye, C. and Raviglione, M. (2009) Drivers of Tuberculosis Epidemics: The Role of Risk Factors and Social Determinants. Social Science \& Medicine, 68, 2240-2246. http://dx.doi.org/10.1016/j.socscimed.2009.03.041

[13] Quy, H.T., Buu, T.N., Cobelens, F.G., Lan, N.T., Lambregts, C.S. and Borgdorff, M.W. (2006) Drug Resistance among Smear-Positive Tuberculosis Patients in Ho Chi Minh City, Vietnam. The International Journal of Tuberculosis and Lung Disease, 10, 160-166.

[14] Ocheretina, O., Morose, W., Gauthier, M., et al. (2012) Multidrug-Resistant Tuberculosis in Port-au-Prince, Haiti. Revista Panamericana de Salud Pública, 31, 221-224. http://dx.doi.org/10.1590/S1020-49892012000300006

[15] Tatar, D., Senol, G., Cosar, D., Ozacar, R. and Halilcolar, H. (2009) Patterns of Drug Resistance in Pulmonary Tuberculosis Cases in the Izmir District, Turkey. New Microbiologica, 32, 31-37.

[16] WHO (2008) Anti-Tuberculosis Drug Resistance in the World. Guidelines for the Programmatic Management of Drug Resistant Tuberculosis. World Health Organization, Geneva.

[17] Ndung'u, P.W., Kariuki, S., Ng'ang'a, Z. and Revathi, G. (2012) Resistance Patterns of Mycobacterium Tuberculosis Isolates from Pulmonary Tuberculosis Patients in Nairobi. The Journal of Infection in Developing Countries, 6, 33-39.

[18] Trivedi, S.S. and Desai, S.G. (1988) Primary Antituberculosis Drug Resistance and Acquired Rifampicin Resistance in Gujarat, India. Tubercle, 69, 37-42. http://dx.doi.org/10.1016/0041-3879(88)90038-4

[19] Joint Tuberculosis Committee of the British Thoracic Society (2006) Tuberculosis: Clinical Diagnosis and Management of Tuberculosis, and Measures for Its Prevention and Control. BTS Guidelines, 2006 April.

[20] WHO 2011 TB Report: World Health Organization (2011) Global Tuberculosis Control: 2011. WHO, Geneva. 
Scientific Research Publishing (SCIRP) is one of the largest Open Access journal publishers. It is currently publishing more than 200 open access, online, peer-reviewed journals covering a wide range of academic disciplines. SCIRP serves the worldwide academic communities and contributes to the progress and application of science with its publication.

Other selected journals from SCIRP are listed as below. Submit your manuscript to us via either submit@scirp.org or Online Submission Portal.
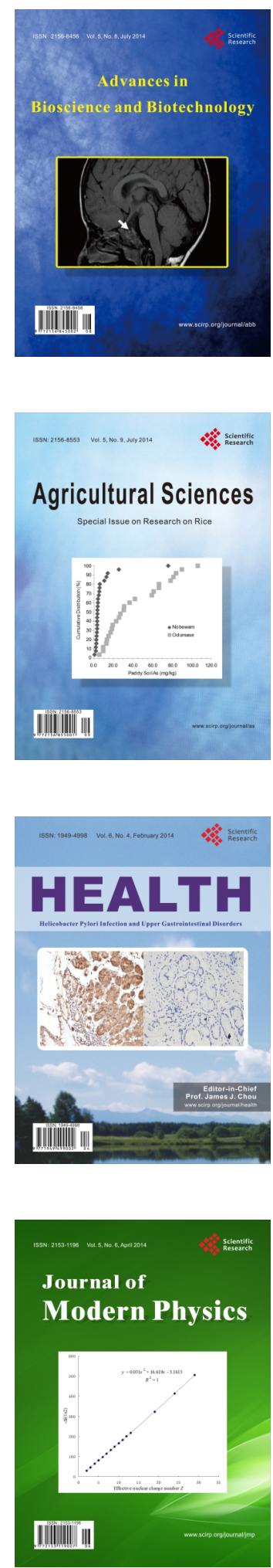
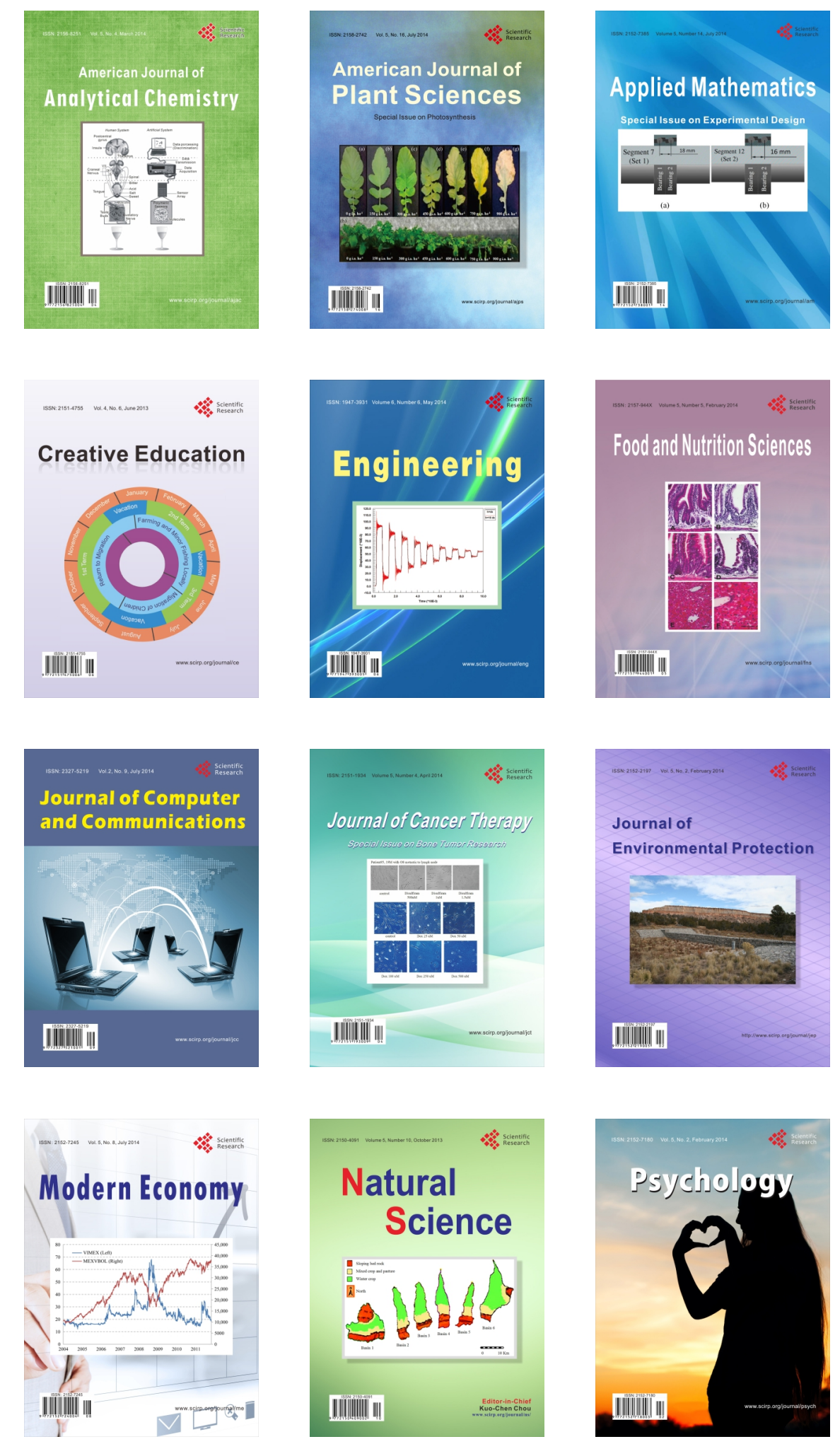